\title{
Direito autoral, MP3 e a nova indústria da música
}

\section{Copyright, MP3 and the new recording industry}

Jose Eduardo Ribeiro de Paiva I eduardopaivacampinas@uol.com.br

Doutor em Multimeios pela Universidade Estadual de Campinas (Unicamp), onde leciona na área de Comunicação e Artes e desenvolve projetos em tecnologia, mídia, produção audiovisual e criação sonora.

\section{Resumo}

Este artigo discute as transformações na indústria fonográfica, desde os anos 90, provocadas pelo formato MP3, que, numa abordagem superficial, é apontado como responsável pelo declínio das vendas de discos e por promover a pirataria fonográfica em escala mundial. Neste recorte, conceitos como autoria, direito autoral e outros têm de ser repensados à luz desta tecnologia, ao mesmo tempo em que se discute seu potencial criativo e sua capacidade de democratizar a produção sonora.

Palavras-Chave: MP3; Indústria fonográfica; Direito autoral.

\begin{abstract}
This article discusses the transformation of the recording industry since the 90s caused by MP3, that, in a first look, has been held responsible for the decline in record sales and to have promoted phonographic piracy in a world scale. In this summary, concepts like authorship and copyrights have been reviewed in light of this technology as well as its creative potential and capacity to democratize sound production are discussed.
\end{abstract}

Keywords: MP3; Recording industry; Copyrights. 
No universo das tecnologias digitais que se instalaram nos meios de produção sonora a partir dos anos 80 , o formato MP3 com certeza foi o que mais impactou a indústria fonográfica. Desenvolvido a partir dos anos 80 , pelo Fraunhofer Institut, teve como base o projeto Eureka ${ }^{1}$, e foi disponibilizado ao público a partir de 1992, sendo sua principal característica a capacidade de reduzir um arquivo digital de áudio em formato .wav (formato nativo padrão da gravação em CD áudio) a 1/12 avos de seu tamanho.

É importante notar que esse desenvolvimento foi mais uma das apropriaçóes tecnológicas realizadas no âmbito da criação sonora, uma vez que o projeto Eureka visava, primeiramente, desenvolver processos de compressão de áudio digital voltados à utilização em processos de comunicação, e posteriormente, os resultados obtidos foram aplicados à música. Isso, de imediato, resolveu o problema do fluxo de arquivos sonoros pela rede, permitindo a troca de arquivos sonoros pela web, que ainda funcionava a taxas de transferência muito baixas, na faixa de $56 \mathrm{~K}$. Esta troca de arquivos se solidificou a partir do surgimento, no fim dos anos 90, dos primeiros serviços $\mathrm{P}^{2} \mathrm{P}^{2}$, do qual o mais famoso foi o Napster, em 1999 (COLEMAN, 2003, p. 189), que foi o catalizador de todas as discussóes sobre troca de arquivos na rede.

Existiram, anteriormente, algumas tentativas de distribuir música legalmente pela web, através de empresas como a Liquid Audio e a Cerberus, que, pela primeira vez, comercializaram a música desvinculada de seu suporte, isto é, apenas a informação sonora que seria transferida diretamente ao computador do usuário. Em praticamente um século de existência, seria a primeira vez que a música seria comercializada sem o papel e o plástico que caracterizaram a indústria fonográfica até os anos 90 .

A Liquid Audio possuía uma tecnologia própria, que contemplava questôes até hoje discutidas, como o pagamento de direitos autorais (PAIVA, 1998, p. 93), e a Cerberus baseava-se no formato MP3. Porém, com o surgimento dos softwares P2P de troca de arquivos pela rede, estas empresas entraram em rápida decadência e desapareceram sem deixar rastros.

É inegável que a possibilidade de distribuição musical sem a necessidade física da vinculação a um suporte, através do formato MP3, trouxe um grande número de alteraçôes aos mecanismos até então utilizados na distribuição musical, e uma série de indagaçóes ligadas ao próprio fazer musical. A primeira e óbvia constatação foi a de que os sistemas de troca de arquivos via rede fizeram com que os números de venda de gravaçóes despencassem, conforme demonstrado no gráfico abaixo (VOGEL, 2011, p. 250), fazendo com que em 2010 os valores e unidades vendidas fossem iguais aos de 1975 , período de uma das históricas crises do mercado de discos ${ }^{3}$. 


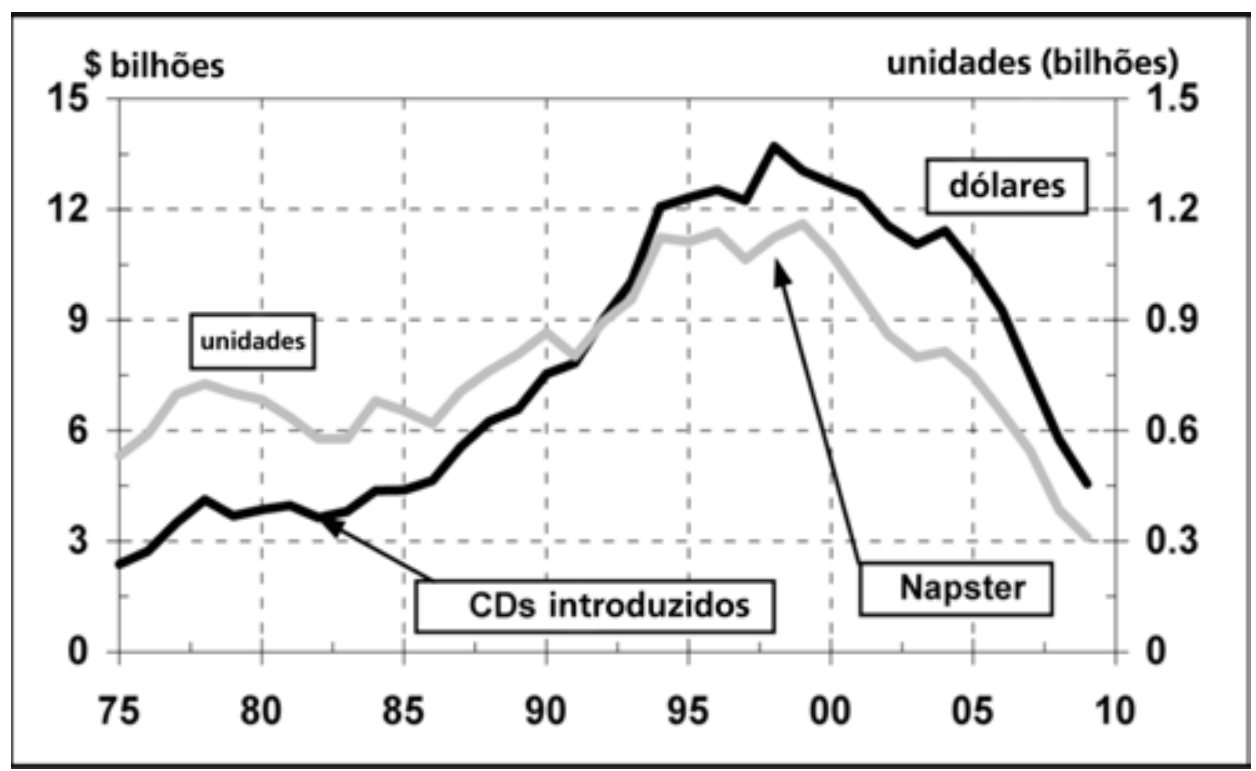

Porém, a queda do volume de vendas foi apenas um dos primeiros choques que o MP3 provocou. O segundo, e maior ainda, foi a possibilidade da distribuição do material musical pela rede sem a necessidade de nenhuma forma de pagamento de direitos autorais, trazendo a questáo da pirataria para o centro da discussão, uma vez que o princípio do direito autoral é um dos grandes fatores de sustentação da indústria fonográfica e do audiovisual. Todo material produzido é passível de recebimento de direito autoral pela sua reprodução pública, e estes valores são particularmente significativos.

No mercado brasileiro, tradicionalmente problemático em relação a este tema, os dados consolidados de 2009 trazem a público o valor de R\$ 318 milhôes recolhidos pelo Escritório Central de Arrecadaçáo de Direitos Autorais (Ecad). Nesse mesmo ano, foram vendidos 20 milhóes de discos, o que, se tomarmos o preço de venda para os lojistas, representa um faturamento de cerca de R \$ 400 milhōes. Ou seja, o valor arrecadado em direitos autorais é, no Brasil, aproximadamente o mesmo valor obtido com a venda de discos. Isto demonstra a importância que o direito autoral tem dentro do mercado fonográfico, onde, ao menos teoricamente, é um valor que se refere diretamente à obra e ao artista, e não à gravadora, o que permite imaginar que, com o advento das tecnologias de distribuição musical via web, os artistas poderiam gerenciar essa fonte de recursos e se livrarem da indústria.

Pode-se colocar que náo somente o MP3, mas todas as tecnologias digitais surgidas a partir dos anos 90 voltadas aos processos de gravação sonora permitiram que a música pudesse ser produzida fora das grandes estruturas empresariais, como percebeu Pierre Lévy:

A partir de agora os músicos podem controlar o conjunto da cadeia de produção da música e eventualmente colocar na rede os produtos de sua criatividade sem passar pelos intermediários que haviam sido introduzidos pelos sistemas de notação e de gravação (LÉVY, 1999, p. 141). 
Através destas tecnologias, e pela primeira vez na história da música gravada, o artista passa a ter controle sobre todas as etapas que compóem o processo de gravação e distribuição musical, do home studio à rede, em uma perspectiva marxista como a citada por Lévy: "Em particular, a evolução contemporânea da informática constitui uma impressionante realização do objetivo marxista da apropriação dos meios de produção pelos próprios produtores" (LÉVY, 1999, p. 245).

Assim sendo, parecia, no fim dos anos 90, que todos os sites de download de arquivos estariam carregados de trabalhos alternativos e à margem da indústria fonográfica, rompendo de vez o monopólio dos grandes selos de gravação mundiais, mas ocorreu justamente o contrário: a web foi massacrada por trocas de arquivos de fonogramas comerciais, protegidos legalmente por direitos autorais, o que resultou em uma grande queda de braço entre as gravadoras e os sistemas de troca P2P, na qual os perdedores até agora têm sido tanto os programas de troca quanto alguns usuários eventualmente processados e, na maioria das vezes, condenados, mundo afora.

O grupo Metallica, em 2000, foi o primeiro, ao menos de forma pública, a mover uma ação judicial contra o Napster pela distribuição de sua obra, o que acabou por levar ao fechamento do serviço e também a uma crescente impopularidade do grupo a partir desta data. Porém, estas atitudes não adiantaram muito, uma vez que o número de downloads ilegais continuou a crescer. Dados divulgados pela Recording Industry Association of America (RIAA), no ano de 2006, mostram que, somente naquele ano, foram baixadas 20 bilhóes de músicas sem o pagamento de direitos autorais.

Alguns conseguiram vislumbrar o potencial comercial da distribuição musical desvinculada do suporte, como Steve Jobs, quando criou o iTunes, em 2003, até hoje a experiência mais bem sucedida na área. Em sua primeira semana de atividades, o serviço registrou um milháo de downloads, a US\$ 0,99 cada (COLEMAN, 2003, p. 207) com grandes medalhôes da música pop entre os primeiros artistas licenciados, de No Doubt a Eagles (idem, p. 206). No Brasil, até hoje não conseguimos uma forma significativa de venda on line $e^{4}$ o que levou o então presidente do Conselho Nacional de Combate à Pirataria, Luiz Paulo Barreto, ainda em 2006, a colocar que não entendia

[...] por que ainda não há no Brasil uma loja virtual nos moldes da iTunes Store, da Apple, que vende milhares de faixas por US\$ 0,99 cada5. "Temos umas quatro ou cinco, mas nelas ou não há disponibilidade de artistas ou os preços são caros", diz. "É melhor vender mil a $R \$ 1$ do que 1 a $R \$ 1.000$. Mas parece às vezes que a indústria está concentrando mercado. Isso é suicídio." (O Estado de S. Paulo, 20 de novembro de 2006).

Historicamente, o preço da música, seja gravada em vinil, CD ou on line, sempre foi caro no Brasil. "O salário mínimo no Brasil não compra 10 LPs" (REIS, 1976, p. 12). Atualmente, a situação é um pouco melhor: se computarmos o preço médio de um $\mathrm{CD}$ a $\mathrm{R} \$ 35$, podemos comprar uma média de quinze discos com um salário mínimo. Porém, se o objeto da compra for música 
on line, a equação é mais complicada: deve-se computar o custo do provedor, o custo do acesso e finalmente o custo do download de cada obra. Esse é um problema específico: o baixo poder aquisitivo e a baixa inclusão digital fazem com que seja difícil a comercialização de discos ou música on line, e, mesmo com o Programa Nacional de Banda Larga, a situação não deve mudar tanto em termos de custo. Em outros países, como o Japão, o cenário é diferente:

Em 2007, o download de música digital no Japão aumentou 56\% em relação a 2006 e chegou aos US\$ 445 milhóes, superando os US\$ 423 milhöes obtidos com a venda de CDs no mesmo periodo. Noventa por cento dos downloads musicais foram feitos por meio de telefones celulares. As vendas de cançôes inteiras aumentaram 150\%, enquanto a comercialização de trechos cresceu 18\%, segundo o jornal Nikkei (Folha de S.Paulo, 24 de fevereiro de 2007).

A venda de música pela internet quase dobrou no mundo todo, no período de 2006 até o presente. Em 2006, os downloads legais apontavam um faturamento de US\$ 2 bilhóes, segundo relatórios da indústria fonográfica. O Relatório de Música Digital em 2007 da Federação Internacional da Indústria Fonográfica (International Federation of the Phonographic Industry - IFPI) informa que os consumidores baixaram, em 2006, 795 milhóes de faixas - aumento de 89\% em relação a 2005 - de quase 500 serviços legalizados de música pela internet em 40 países. O número de faixas disponíveis para baixar dobrou e chega a mais de quatro milhóes nos serviços mais famosos. Pelos dados mais recentes divulgados pela IFPI, em 2010 a venda de música on line representou $29 \%$ do faturamento das gravadoras, movimentando o valor de U\$ 4,6 bilhóes, o que demonstra um crescimento considerável.

É interessante notar que, ao falar em música pela Internet, tudo está dentro de uma escala de consumo globalizada, pois o MP3 é, antes de tudo, o primeiro formato de distribuição musical totalmente globalizado, justamente por estar na esfera do virtual, sem a necessidade do suporte físico. Todos os formatos anteriores, digitais ou analógicos, necessitavam de uma estrutura física de distribuição, sujeita às limitaçôes inerentes destas estruturas. No mundo virtual, o acesso à informação é instantâneo, e qualquer ouvinte pode acessar uma música de onde ele queira, sem nenhuma limitação, o que fez a música experimentar uma velocidade de divulgação até então impensável. Como diz Negroponte (1995, p. 55), "bits não ficam presos em alfândegas".

Outros mercados decorrentes da digitalização e da praticidade do formato MP3 surgem e desaparecem a cada dia, como o de ringtones. Em uma entrevista, em 2007, quando do auge deste mercado, Cris Martin, líder do Coldplay, colocava a importância comercial desse novo formato: "Hoje, uma música tem que ser boa para virar um ringtone. É isso o que interessa (para o mercado)" (Folha On Line, 28 de fevereiro de 2007). Porém, com este mercado aconteceu o inverso: ele experimenta um decréscimo bastante significativo, ao cair de US\$ 5 bilhóes em 2006 para US\$1,5 bilhão (GALO, Istoé Dinheiro, edição 678).

Porém, apesar de ser indubitavelmente o formato de hoje para a distribuição musical, quando examinado pelo viés técnico, o MP3 possui algumas 
limitaçóes em sua qualidade quando comparados ao arquivo original, principalmente pela perda nas altas frequências e eliminação de alguns sons em baixo volume (PAIVA, 2006, pp. 96-97). Isso vai na contramão da tecnologia, que desenvolve sistemas de gravação digital com resolução cada vez mais alta, e o formato MP3 acaba comprimindo o arquivo final com uma série de perdas de dinâmica e frequência, que, por mais que se tente, jamais poderão ser reincorporados ao arquivo original.

Apenas para exemplificação, hoje os sistemas de gravação digitais profissionais chegam a gravar em 24 bits e $192 \mathrm{KHz}$, e os sistemas voltados a home studios, em 24 bits por $96 \mathrm{Khz}$, utilizando conversores analógicos digitais de excelente qualidade, voltados para gravar de forma cada vez mais fiel todas as nuances que compóem o espectro sonoro. Com certeza, qualquer gravação realizada em sistemas desse porte, quando comprimida para o formato MP3, perderá boa parte da qualidade sonora que é o seu diferencial. Isso cria uma dicotomia preocupante, na medida em que se busca uma qualidade sonora cada vez mais sofisticada nos estúdios de gravação, e se ouve sons cada vez mais comprimidos, principalmente em reprodutores portáteis individuais, muitos de baixa qualidade sonora.

Ao se pensar que milhóes de pessoas hoje têm acesso à música através destes reprodutores conectados a fones de ouvido, pode-se imaginar que, daqui a algum tempo, o senso comum da qualidade técnica de uma gravação será muito inferior ao de hoje. Por outro lado, não há como negar que o MP3 é o formato principal das máquinas de convergência da cibercultura, como os celulares, responsáveis por boa parte dos downloads de música via rede hoje.

A audição musical recente sempre apontou para a mobilidade, principalmente a partir do surgimento dos desajeitados e pesados walkmen nos anos 80 , uma vez que sempre estavam ligados à reprodução de um suporte, como a fita cassete e posteriormente o CD. Hoje, com as conexóes via rede dos celulares e outros dispositivos, como os tablets, a música é obrigatoriamente móvel, e aí o MP3 reina soberano.

Apesar das limitações técnicas, é interessante que se examine também as questóes referentes ao MP3 no processo criativo, através dos milhares de samples e loops que estáo disponíveis na rede nesse formato, servindo de base para diversas criaçóes sonoras. Não que antes não existissem essas possibilidades, uma vez que a música techno, por exemplo, surgiu ainda nos anos 80; mas a possibilidade de que milhóes de arquivos pudessem ser compartilhados, manipulados e editados por usuários, muitas vezes anonimamente, pelo mundo todo é uma decorrência do formato MP3. A música, antes composta nota a nota em um papel e instrumento, em grande parte hoje é realizada através de amostras de outras músicas, que são montadas digitalmente em diversos softwares, o que acaba por se tornar uma espécie de marca registrada da cibercultura (LÉVY, 1999, p. 17) em que vivemos hoje.

É cada vez mais frequente que os músicos produzam sua música a partir da amostragem e da reordenaçáo de sons, algumas vezes trechos inteiros, previamente obtidos no estoque das gravaçôes disponíveis. Essas músicas 
feitas a partir de amostragens podem, por sua vez, ser também objeto de novas amostragens, mixagens e transformaçóes diversas por outros músicos, e assim por diante (idem, p. 141).

O desenvolvimento de softwares voltados à criação musical traz a capacidade do músico trabalhar não mais sobre nota a nota no processo de composição, mas sim sobre eventos completos e trechos de áudio de outras cançôes, algo que teve seu início nas experiências de world music dos anos $80 \mathrm{com}$ artistas como Peter Gabriel, e que hoje, com a popularizaçáo da tecnologia e os samplers, tornou-se acessível, inclusive aos não músicos, desde que saibam manipular corretamente os softwares de edição de áudio.

Essa é uma das grandes discussóes que hoje envolvem tecnologia e criação sonora: até onde é necessário um real conhecimento de música para que se possa compor a partir de loops e samplings? Dentro da evoluçáo da tecnologia aplicada à criação sonora e musical, isso jamais havia sido possível até o surgimento dos softwares e dos milhóes de amostras em MP3 que trafegam pela rede. Pelo contrário, algumas tecnologias exigiam profundo conhecimento musical para serem corretamente utilizadas, como a técnica de gravação multipista que necessita de um conhecimento bastante profundo de orquestração e arranjo para sua plena utilização. Manipular um software como Acid ou Reason exige muito mais um profundo conhecimento técnico que musical, no sentido definido por Aumont (1993, p. 178) de técnica como manipulação da tecnologia.

Com isso, surge uma nova geração de artistas que náo se sabe ao certo como defini-los, se como criadores, tecnólogos, híbridos que se expressam unicamente pela tecnologia, algo que teve início com os DJs da década de 80 e seus procedimentos que os aproximavam do ready made de Duchamp, como os exercícios de colagem, citação e bricolagem existentes na sua música. Porém, mais do que os exercícios citados, que antigamente eram praticados sobre músicas e discos criados com essa finalidade específica, hoje o MP3 disponibiliza na rede milhóes de amostras anônimas, que acabam por ser utilizadas novamente por milhóes de outros criadores, e muitas vezes não será fixada em nenhum suporte: sua duração será apenas até ser deletada pela última vez, sem deixar vestígios da sua existência e sem que se possa afirmar claramente quem é o seu autor.

Esse procedimento contraria os mais de cem anos de música gravada em algum tipo de suporte, onde registrar o trabalho era a proposta fundamental dos artistas, que viam na capacidade de venda do suporte a possibilidade do sucesso e, especificamente na música erudita, a possibilidade do reconhecimento da crítica e do público pela comparação com outras gravações e intérpretes. E, acima de tudo, o registro em um suporte dava uma materialidade à música e a preservava historicamente. Em um tempo de efemeridades, em que não há nem o suporte da obra gravada nem o suporte da partitura, a música deixa de ser preservada, e com isso muitos paradigmas da estética deverão ser repensados.

Um caso emblemático que envolve a questão da autoria no mundo digital é o referente à pianista Joyce Hatto, que lançou uma série de gravaçóes póstumas produzidas pelo seu marido, o produtor William Barrington-Coupe, sendo muitas delas premiadas pelas mais importantes revistas da área erudita 
(O Estado de S. Paulo, Caderno 2, 27 de fevereiro de 2007). Tudo era uma fraude, com seu marido se apropriando de gravações de outros intérpretes e as colocando sob o nome de Joyce, o que provocou uma série de indagaçóes sobre as questôes da autoria no universo digital, onde as cópias, por serem cópias de códigos numéricos, sempre serão iguais aos originais.

E, aqui, mais uma vez, a questão dos direitos autorais: se não se pode atribuir com certeza um autor a uma obra também não existem direitos autorais decorrentes de sua utilização. Porém, se um compositor compóe uma obra a partir de uma série destes loops anônimos, e a registra como de sua autoria, ele passa a receber direitos sobre esta composiçấo ${ }^{6}$. Isto deixa clara a confusão que hoje existe sobre este tema, que está sendo repensado em diversas instâncias legais de muitos países, inclusive no Brasil.

$\mathrm{O}$ ar de novidade tecnológica e modernidade contida na criação musical sobre samples e loops de áudio que servem simultaneamente a centenas de composiçóes, assim como quase toda a maioria da tecnologia utilizada na música popular remetem a Adorno e sua discussão sobre indústria cultural.

[... o insistentemente novo que ela (a indústria cultural) oferece permanece em todos
os seus ramos, a mudança de indumentária de um sempre semelhante; em toda parte a
mudança encobre um esqueleto no qual houve tão poucas mudanças como na própria
motivaçáo do lucro desde que ela ganhou ascendência sobre a cultura. (ADORNO,
1987, p. 289).

A música produzida assim não difere em nada da produzida pelos modos tradicionais, reafirmando os modelos da música pop de consumo produzida desde o surgimento do rock'n'roll até a atualidade, esquecendo as possibilidades expressivas destas novas tecnologias. Pior que isso, a maior parte dos softwares ou hardwares dedicados à criação musical hoje baseiam-se em ferramentas capazes de gerenciar essas amostras de áudio de forma ininterrupta, fazendo com que a composição seja muito mais um exercício de copy and paste do que um real processo criativo, onde elementos como variação rítmica e dinâmicas são valorizados.

Um exemplo sonoro clássico é o que se chama de música eletrônica de hoje: longe dos experimentos da segunda metade do século XX de compositores como Pierre Schaeffer, Pierre Henry ou Stockhausen, o termo hoje se aplica a música de pista, onde as longas repetiçóes rítmicas e a limitada dinâmica são uma constante.

Neste cenário de transição do real ao virtual, a web é, sem dúvida alguma, o novo território para a circulação musical, e o MP3, seu principal formato. Mas, em um novo ciclo de apropriaçóes tecnológicas, movimentos como o tecnobrega do Pará ou o funk carioca se apropriaram dessa tecnologia de forma significativa e, se hoje movimentam multidóes de fãs, é justamente por terem utilizado o MP3 e a web como ferramentas de divulgaçáo e comercialização, em um sólido processo de democratização dos meios de produção e circulação, indo contra todos os princípios do direito autoral. 
Produzido com alta tecnologia (o MP3 é sua mídia oficial), divulgado pelas rádios locais e centenas de aparelhagens (gigantescas paredes de caixas de som que chegam a reunir 5 mil pessoas por noite, quatro vezes por semana) e dissipado por camelôs (a pirataria é seu grande divulgador), o tecnobrega fomenta um novo modelo de (ou "para a") indústria fonográfica (BITTENCOURT, 2007).

$\mathrm{O}$ artista aqui não vive mais do direito autoral nem da arrecadação da venda de discos: estes são apenas ferramentas de divulgação para que seu trabalho seja contratado, e a pirataria é a forma de divulgação e distribuição oficial do movimento.

O que torna o tecnobrega particular é que os artistas que o produzem não têm gravadoras. Eles enviam suas cançóes para as rádios em formato MP3. Fazem o mesmo com os camelôs, que se encarregam de produzir os CDs para vender nas ruas, arcando com os custos de prensagem e impressão das capas. Ou seja, as gravadoras são o quintal da casa dos camelôs. Alguns CDs são gravados ao vivo e vendidos já na saída do show. (Ministério da Cultura, Fóruns de Cultura, Propriedade Intelectual em xeque, 2006).

À margem do mundo oficial, dos impostos, gravadoras e direitos autorais, a tecnologia vai recriando a cidadania e a expressão de uma geração que não teve seu rosto espelhado no universo midiático estabelecido, e esta geração vem trazer ao mundo estabelecido da indústria novos modelos de trabalho. Aqui se encontram as premissas que se imaginava quando do surgimento da rede, na questão da democratização e circulação de obras de autores anônimos e à margem da indústria de então.

Neste processo de apropriação, diferentes formas de utilização da tecnologia e da gravação são apreendidas e criadas quase que diariamente levando em conta as necessidades específicas de diversos grupos sociais brasileiros, como o relato abaixo demonstra.
[...] indagado sobre sua vida, o indio contou que nos últimos tempos vinha empreendendo um trabalho de resgate da cultura de sua tribo, sendo ele um dos líderes deste povo. Uma das decisóes tomadas foi enviar duas moças desta tribo para a floresta no intuito de lá recolherem "a tradição" do povo. As moças passaram um ano na floresta e nesta estada os espiritos dos ancestrais lhes contaram seus cantos "tradicionais". De volta à tribo, as moças então espalharam para todos estes cantos, reunindo aquele povo ao seu passado imemorial e mitico. David, satisfeito com a história, disse ao indio que adoraria ouvir seus cantos. $O$ indio não tardou. Prestativo e orgulhoso, retirou da mala ao seu lado um computador Macintosh e tocou "os cantos", inclusive em versão remix. Na despedida, o indio colocou à venda os CDs, com encarte em inglês, para David (NETTO, 2009, p. 119)

O MP3 é apenas a ponta deste iceberg digital que abalroou a indústria fonográfica, e nada, nos mais de cem anos desta indústria, causou impactos táo profundos. Disso, em meio ao furação e ao turbilhão de poeira que ainda cobre a tudo e a todos, claramente, apenas uma certeza, e esta se aplica à totalidade dos mercados fonográficos do mundo: "as gravadoras terão de aprender a comercializar informaçôes e não mais suportes físicos” (PICCINO, 2006, p. 102). 
Além disso, o termo "mercado fonográfico" parece obsoleto para definir um mundo onde cada um é capaz de gerenciar seu próprio meio de criação e distribuição musical, onde os excluídos da mídia podem ter voz e circulação. Extrapolando para a criaçáo audiovisual, algo semelhante ao ocorrido na Nigéria, que se tornou um dos maiores produtores mundiais de cinema.

O último atlas do cinema mundial feito pela prestigiosa revista Cahiers du Cinema inclui a Nigéria entre os maiores produtores de filmes do mundo (mais de 1.200 por ano). Algo muito curioso para um país que simplesmente não possui salas de cinema. $O$ milagre deve-se ao surgimento de um mercado de filmes feitos para serem vendidos diretamente em DVD. E ainda mais interessante: por camelôs - todos os filmes são vendidos nas ruas, por menos de três dólares (LEMOS, 2006).

Com as tecnologias digitais e a internet, toda uma nova série de músicos, produtores, DJs, hoje tem acesso aos meios de produção, e principalmente, ao meio de circulação da produção sonora. Um processo irreversível, em que todo o mercado fonográfico do século XX e suas principais questóes têm de ser repensados e rearranjados, em busca de sua sobrevivência no mundo virtual, onde os suportes de papel e plástico não têm vez.

Ao mesmo tempo, este novo mercado virtual traz voz e rosto a centenas de grupos excluídos no processo tradicional da indústria, com obras que muitas vezes podem ser questionadas em relação ao seu conteúdo musical, como acontece com a funk carioca, mas onde se revela uma grande revoluçáo na produção audiovisual que ocorre pela utilização destas novas tecnologias.

E é isso que faz deste momento que vivemos tão interessante: a busca da capacidade de sobreviver em meio a um furacáo que está varrendo todos os paradigmas da criação e distribuição sonora, e, por que não, audiovisual, e de como a indústria musical se posicionará nos próximos anos. Uma pista disto foi dada durante a escrita deste artigo, quando os EUA tentaram aprovar as leis SOPA (Stop Online Piracy) e PIPA (Protect Intellectual Property Act), inclusive com açôes de prisão contra proprietários de sites de compartilhamento, dos quais a mais significativa foi a de Mathias Ortmann (Kim Dotcom), proprietário do site Megaupload. Este site respondia pelo tráfego de 4\% de todos os dados da internet, e tudo aponta para que sua prisão náo tenha sido apenas pela violaçáo de direito autoral, mas pelo modelo revolucionário de negócios que o site lançaria este ano, que contribuiria para quebrar o monopólio das gravadoras (BURNS, 2012).

Independentemente da razão, se a indústria fonográfica e do audiovisual adotarem este caminho, será a prova definitiva de que não compreenderam as potencialidades da rede e do mundo digital. 


\section{Referências bibliográficas}

ADORNO, T. W. A indústria cultural. In: COHN, Gabriel (org.). Comunicação e Indústria Cultural, 5ª ed. Sáo Paulo: T.A. Queiroz, 1987.

AUMONT, Jacques. A imagem. Campinas: Papirus, 1993.

BITTENCOURT, Bruna. 2007. Guerrilha dos toca discos. Disponível em: http://cakito.multiply.com/journal/item/24/Guerrilha_dos_toca-discos. Consultado em: 1/5/2011.

BURNS, Matt. 2012. Was Megaupload Targeted Beacuse of its Upcoming Megabox Digital Jukebos Service? Disponível em: http://techcrunch. com/2012/01/24/was-megaupload-targeted-because-of-its-upcoming-megabox-digital-jukebox-service/. Consultado em: 25/1/2012.

LÉVY, Pierre. Cibercultura. São Paulo: Editora 34, 2005.

LEMOS, Ronaldo. Cinema Povo. Disponível em: http://www.culturalivre.org.br/wp/pt/2006/02/17/cinema-povo/. Consultado em: $12 / 12 / 2007$

NETTO, Michel Nicolau. Música brasileira e identidade nacional na mundialização. São Paulo: AnnaBlumme, 2009.

NEGROPONTE, N. A vida digital. São Paulo: Companhia das Letras, 1995.

PAIVA, J. E. R. MP3 na contramão da história, Diapason 4, 96-97, São Paulo, 2006.

Tecnologias de compressão de áudio digital e novas possibilidades musicais. Cadernos da Pós Graduaçáo 2, 91-97, Campinas, 1998.

PICCINO, Evaldo. Mudanças de suportes sonoros no mercado fonográfico brasileiro. Capitulos digitais e analógicos de uma novela muito antiga. Dissertação de Mestrado: IA-Unicamp, Campinas, 2007.

VOGEL, Harold L. Entertainment industry economics. New York: Cambridge University Press, 2011.

\section{Notas}

1. O projeto Eureka destinava-se a desenvolver processos de compressáo de áudio digital voltados à transmissão de sinais sonoros em alta qualidade pela linha telefônica. A partir do estabelecimento do grupo de trabalho MPEG (Moving Picture Experts Group) foram criados os padrôes MPEG utilizados hoje em áudio e vídeo.

2. Uma rede Peer-to-Peer (P2P) é constituída por computadores ou outros tipos de unidades de processamento que não possuem um papel fixo de cliente ou servidor, pelo contrário, costumam ser considerados de igual nível e assumem o papel de cliente ou de servidor dependendo da transação.

3. Neste período, houve a crise de petróleo, com um aumento de $300 \%$ no preço do barril, o que impactou fortemente o fornecimento da massa vinílica utilizada para a fabricação dos discos de vinil.

4. Nas vendas feitas pelo iTunes, o valor é assim distribuído: $14 \%$ ao artista, 30\% para o 
iTunes e 56\% para o selo de gravaçóes, enquanto, na venda de CDs, os direitos chegam a até 25\% (VOGEL, 2011, p. 267).

5. Em dezembro de 2011, o iTunes foi inaugurado no Brasil, com um acervo de 20 milhóes de cançôes, ao preço médio de R \$ 1,80 cada. Imediatamente, uma polêmica: a loja virtual colocou à venda as cançóes do disco Louco por você, álbum de estreia de Roberto Carlos, sem a autorização do autor. Cf. http://www1.folha.uol.com.br/ilustrada/1040623roberto-carlos-notifica-itunes-por-vender-disco-renegado-de-1961.shtml.

6. Esta discussão é antiga, e encontrada com frequência na obra de compositores como Bela Bartók ou Heitor Villa-Lobos, que muitas vezes trabalharam sobre temas folclóricos (como exemplo, o Guia Prático, de Villa), mas que têm as obras finais creditadas como de autoria própria. 